\title{
Nestin expression in high-grade osteosarcomas and its clinical significance
}

\author{
IVA ZAMBO $^{1}$, MARKETA HERMANOVA ${ }^{1}$, DAGMAR ADAMKOVA KRAKOROVA ${ }^{2}$, PETER MUDRY ${ }^{3}$, \\ KAREL ZITTERBART ${ }^{3}$, MICHAL KYR ${ }^{3}$, KAREL VESELY ${ }^{1}$, JAROSLAV STERBA ${ }^{3}$ and RENATA VESELSKA ${ }^{3,4}$ \\ ${ }^{1}$ First Department of Pathological Anatomy, Medical Faculty of Masaryk University and St. Anne's University Hospital, \\ Pekarska 53, 65691 Brno; ${ }^{2}$ Department of Complex Oncology Care, Masaryk Memorial Center Institute, \\ Zluty Kopec 7, 65653 Brno; ${ }^{3}$ Department of Pediatric Oncology, University Hospital Brno, Cernopolni 9, \\ 61300 Brno; ${ }^{4}$ Laboratory of Tumor Biology, Department of Experimental Biology, School \\ of Science, Masaryk University, Kotlarska 2, 61137 Brno, Czech Republic
}

Received November 30, 2011; Accepted January 16, 2012

DOI: 10.3892/or.2012.1687

\begin{abstract}
Nestin has been detected in various malignancies and its expression correlates with advanced grade in some neoplasms. The aim of this study was to examine nestin expression in high-grade osteosarcomas and to determine its prognostic value. Using immunohistochemistry and immunofluorescence, we evaluated nestin expression in tumor tissue samples from 45 patients with high-grade osteosarcomas. In both methods, the frequency of nestin-positive tumor cells was classified into three categories $(1+, 2+$ and $3+$ for immunohistochemistry; $1 \mathrm{~F}+, 2 \mathrm{~F}+$ and $3 \mathrm{~F}+$ for immunofluorescence) and clinicopathological correlations were statistically evaluated and analyzed. Nestin-positive tumor cells were detected in all of the examined osteosarcomas using both immunohistochemistry and immunofluorescence, although the proportion of undoubtedly positive neoplastic cells varied in individual samples from a few nestin-positive tumor cells to diffuse nestin positivity. High levels of nestin expression detected by immunofluorescence $(2 \mathrm{~F}+$ and $3 \mathrm{~F}+)$ were associated with worse clinical outcomes (OS, $\mathrm{P}=0.031$; EFS, $\mathrm{P}<0.001)$. However, high levels of nestin expression as measured by immunohistochemistry trended towards shorter patient survival rates but did not reach statistical significance. Despite significantly shorter survival rates observed in patients with high levels of nestin expression assessed by immunofluorescence, nestin does not seem to represent a powerful prognostic marker that would be superior to conventional methods.
\end{abstract}

Correspondence to: Dr Marketa Hermanova, First Department of Pathological Anatomy, Medical Faculty of Masaryk University and St. Anne's University Hospital, Pekarska 53, 65691 Brno, Czech Republic

E-mail: marketa.hermanova@fnusa.cz

Keywords: osteosarcoma, nestin, prognosis,immunohistochemistry, immunofluorescence

\section{Introduction}

Osteosarcoma, in which the neoplastic cells produce osteoid and/or bone, is the most common primary malignant bone tumor. The disease affects males more frequently than females and typically occurs during growth spurts in adolescents and young adults. However, a second, smaller peak of osteosarcoma incidence has been observed after the sixth decade of life (1). Although the majority of osteosarcomas occur sporadically, there are a few proven risk factors, e.g., familial cancer syndromes (2-5), Paget's disease of bone or previous exposure to ionizing radiation $(6,7)$.

Gross metastatic disease occurs in approximately $20 \%$ of patients at diagnosis (8), and distant metastases are typically found in the lungs or bone. The current therapeutic approach incorporates the radical removal of the primary tumor and/ or metastases in combination with aggressive, systemic polychemotherapy. In osteosarcoma patients, radiation has been found to be ineffective, and thus, external beam radiotherapy is reserved for palliative treatment only. Patient outcomes are predicted by the percent of histologically assessed tumor necrosis in the resected specimen after preoperative chemotherapy (9). Patients who have achieved greater than $90 \%$ tumor necrosis are referred to as good responders. On the contrary, poor responders are those with less than $90 \%$ necrosis in the resected specimen (10).

Despite advances in osteosarcoma treatment within the past 30 years, the success rates of current therapies have reached a plateau (11). The 5-year survival rate for poor-responders and for patients with primary metastatic disease remains at 45-60\% $(12,13)$ and 10-40\% (14), respectively. Furthermore, osteosarcoma is the second leading cause of cancer-related death in children and young adults (15). Hence, there is a real need to develop novel therapeutic approaches for patients with osteosarcomas.

Nestin is a type VI intermediate filament protein expressed in proliferating cells during the early stages of embryogenesis (16). During differentiation, nestin is down-regulated and replaced by other tissue-specific intermediate filament proteins 
$(17,18)$. Although the biological function of nestin is not yet fully elucidated, it has been implicated in the distribution and organization of critical molecules that regulate cell proliferation, survival and differentiation (19-21). Nestin expression is re-induced during pathology-related repair processes in the CNS, muscle, liver and infarcted myocardium (22-25). Nestin expression has also been observed in various neoplasias, including gastrointestinal stromal tumors (26), brain tumors (27), prostate cancer (28), melanoma (29), osteosarcoma (30), dermatofibrosarcoma protuberans (31) and thyroid tumors (32). Furthermore, nestin is closely correlated with tumor angiogenesis, as it is also highly expressed in proliferating vascular endothelial cells (33-35). Additionally, nestin is widely considered to be a cancer stem cell marker in nervous system tumors (36-38), prostate cancer $(39,40)$, pancreatic cancer $(41)$, bladder cancer (42), and malignant rhabdoid tumors (43). In our most recent study, we also demonstrated both the in vitro and in vivo tumorigenicity of cells co-expressing nestin and CD133 in rhabdomyosarcomas (44).

A separate report from our group was the first to describe nestin expression in osteosarcomas and osteosarcoma cell lines (30). The aim of the present study was: i) to examine expression of nestin by immunodetection methods in tumor samples obtained from 45 patients with high-grade osteosarcoma, ii) to investigate a possible correlation between nestin expression and clinicopathological variables, and iii) to determine the prognostic value of nestin expression in osteosarcomas.

\section{Materials and methods}

Study group and tissue specimens. The study cohort consisted of 45 patients with high-grade osteosarcoma [24 males $(53.3 \%)$ and 21 females (46.7\%); median age 19 years (range, 6-85 years)] who had undergone surgical intervention at the St. Anne's University Hospital or the University Hospital Brno during 1997-2010. Almost all patients received a standard treatment consisting of preoperative chemotherapy followed by surgical resection and adjuvant chemotherapy with or without external beam radiotherapy. A combination of cisplatin, doxorubicin or adriamycin, and high-dose methotrexate was used as a chemotherapy induction regimen. Patients over 50 years of age received only adriamycin and cisplatin. The same combination of cytostatic drugs was applied in adjuvant chemotherapy. In the presence of metastatic disease, ifosfamide or etoposide were also used.

Based on current WHO classification, four histological subtypes of high-grade osteosarcoma were identified: osteoblastic (28 cases; $62.2 \%$ ), chondroblastic ( 7 cases; $15.6 \%$ ), fibroblastic (6 cases; $13.3 \%$ ), and teleangiectatic (4 cases; $8.9 \%$ ). Tumor staging was performed using the Enneking staging system, which is based on the presence of intracompartmental and extracompartmental extension of the tumor as well as on the tumor grade and the presence of metastases. In addition, tumor staging according to the International Union Against Cancer TNM System (6th edition) is also included in Table I.

Tumor samples obtained during initial biopsies were fixed in $10 \%$ neutral buffered formalin and embedded in paraffin. Hematoxylin-eosin (H\&E) stained tissue sections were histologically examined by two pathologists (I.Z. and M.H.), and representative tissue blocks were selected for immunohisto-
Table I. Characteristics of the patient cohort.

\begin{tabular}{|c|c|}
\hline Variable & $\mathrm{N}(\%)$ \\
\hline \multicolumn{2}{|l|}{ Age } \\
\hline$<19$ & $22(48.9)$ \\
\hline$\geq 19$ & $23(51.1)$ \\
\hline \multicolumn{2}{|l|}{ Gender } \\
\hline Male & $24(53.3)$ \\
\hline Female & $21(46.7)$ \\
\hline \multicolumn{2}{|c|}{ Histologic subtype } \\
\hline Osteoblastic & $28(62.2)$ \\
\hline Chondroblastic & $7(15.6)$ \\
\hline Fibroblastic & $6(13.3)$ \\
\hline Teleangiectatic & $4(8.9)$ \\
\hline \multicolumn{2}{|l|}{ Stage (Enneking) } \\
\hline IIA & $5(11.1)$ \\
\hline IIB & $31(68.9)$ \\
\hline IIIA & $1(2.2)$ \\
\hline IIIB & $8(17.8)$ \\
\hline \multicolumn{2}{|l|}{ T category } \\
\hline 1 & $6(13.3)$ \\
\hline 2 & $36(80.0)$ \\
\hline 3 & $3(6.7)$ \\
\hline \multicolumn{2}{|l|}{$\mathrm{N}$ category } \\
\hline 0 & $41(91.1)$ \\
\hline 1 & $2(4.4)$ \\
\hline $\mathrm{X}$ & $2(4.4)$ \\
\hline \multicolumn{2}{|l|}{ M category } \\
\hline 0 & $36(80.0)$ \\
\hline $1 \mathrm{a}$ & $2(4.4)$ \\
\hline $1 b$ & $6(13.3)$ \\
\hline $\mathrm{X}$ & $1(2.2)$ \\
\hline \multicolumn{2}{|c|}{ Neoadjuvant chemotherapy } \\
\hline Yes & $43(95.6)$ \\
\hline \multicolumn{2}{|l|}{ Radical surgery } \\
\hline Yes & $36(80.0)$ \\
\hline \multicolumn{2}{|c|}{ Adjuvant chemotherapy } \\
\hline Yes & $38(84.4)$ \\
\hline \multicolumn{2}{|c|}{ Continuous remission } \\
\hline Yes & $31(68.9)$ \\
\hline \multicolumn{2}{|l|}{ Relapse } \\
\hline Yes & $23(51.1)$ \\
\hline \multicolumn{2}{|l|}{ Deceased } \\
\hline Yes & $21(46.7)$ \\
\hline
\end{tabular}

chemical and immunofluorescence analyses. Furthermore, some results of these analyses were confirmed using tissue samples of recurrent or metastatic osteosarcomas. A total of 35 samples were not ossified and were not subjected to decalcification, and ten cases were decalcified using $8 \%$ hydrochloric acid with ferric chloride. 


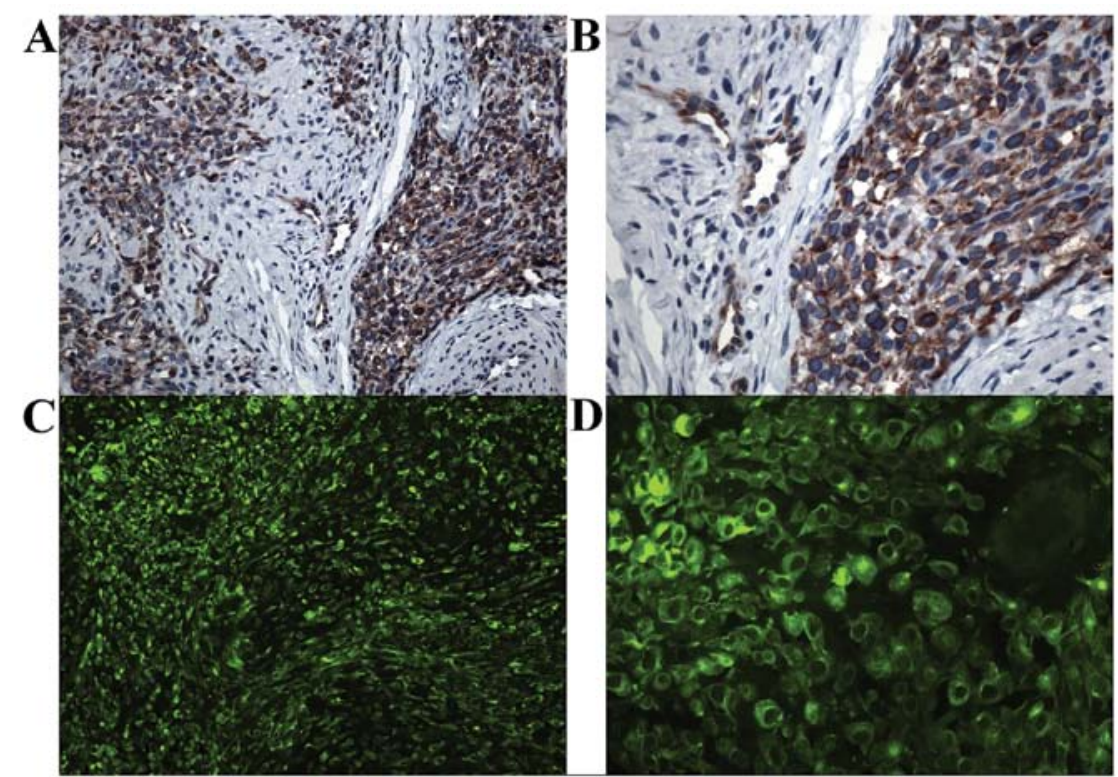

Figure 1. Immunohistochemical and immunofluorescence analyses of nestin expression in high-grade osteosarcomas. (A and B) Strong cytoplasmic nestin immunohistochemical staining in a majority of tumor cells with an internal positive control of nestin-positive endothelial cells. (C and D) Nestin expression in a significant proportion of tumor cells as evaluated by indirect immunofluorescence. Original magnification (A and C, x200); (B and D, x400).

A written statement of informed consent was obtained from each subject or guardian and the research ethics committees of the involved hospitals approved the study protocol. The data summarized in Table I were retrieved from clinical documents.

Immunohistochemistry. The immunohistochemical detection of nestin expression was performed on $4-\mu \mathrm{m}$ thick tissue sections applied to positively-charged slides. The sections were deparaffinized in xylene and rehydrated through a graded alcohol series. Antigen retrieval was performed in a Pascal calibrated pressure chamber (Dako, Glostrup, Denmark) by heating sections to $97^{\circ} \mathrm{C}$ in Tris/EDTA buffer ( $\mathrm{pH} 9.0$ ) for $40 \mathrm{~min}$. Endogenous peroxidase activity was quenched with $3 \%$ hydrogen peroxide in methanol for 10 min followed by incubation with a mouse monoclonal antibody to nestin (clone 10C2, dilution 1:200, Millipore, Billerica, MA, USA) at room temperature for $90 \mathrm{~min}$. A streptavidin-biotin peroxidase detection system was used according to the manufacturer's instructions (Vectastain Ellite ABC Kit, Vector Laboratories, Burlingame, CA, USA). The reaction was visualized using 3,3'-diaminobenzidine tetrahydrochloride (DAB, Dako), and the slides were then counterstained with Gill's hematoxylin. Negative controls were performed by incubating samples without the primary antibody. Tissue sections of glioblastoma multiforme served as external positive controls for the anti-nestin antibody, and nestin-positive endothelial cells in osteosarcoma tissue samples were used as internal positive controls. The evaluation of immunohistochemical results was performed using a uniform microscope and camera setting (Olympus BX51 microscope and DP70 camera).

Immunofluorescence. Following the initial procedures described above, tissue sections were incubated with a mouse monoclonal anti-nestin antibody (clone 10C2, dilution 1:200,
Millipore) at room temperature for $90 \mathrm{~min}$. A secondary antibody, i.e., goat anti-mouse antibody conjugated to FITC (No. AP124F, dilution 1:50, Millipore), was then applied for $60 \mathrm{~min}$ before the slides were mounted with a mounting medium (No. S3025, Faramount Aqueous Mounting Medium, Dako). A uniform microscope and camera setting (Nikon Eclipse 80i microscope and DS-Fil camera) were used for evaluation of immunofluorescence results. Micrographs were analyzed using NIS-Elements BR 3.0 software (Nikon Instruments, Laboratory Imaging, Ltd., Czech Republic).

Evaluation of immunostaining. In tumor cells (TC), cytoplasmic immunostaining for nestin was considered to be positive (Fig. 1). The percentages of positive TCs were independently assessed by two observers (I.Z. and M.H.) with no prior knowledge of clinical details, using both light and fluorescent microscopes at $\mathrm{x} 400$ magnification. Disagreements between observers were resolved by a consensus.

For immunohistochemical detection, at least five representative microscopic fields were analyzed, and the average percentage of nestin-positive TCs of the entire covered area was scored. The proportions of nestin-positive TCs were divided into three levels: $1+(<10 \%$ nestin-positive TCs), $2+$ (10-50\% nestin-positive TCs), and $3+$ ( $>50 \%$ nestin-positive TCs); levels 1, 2 and 3.

In nestin immunofluorescence, the frequencies of clearly positive cells were stratified into the following levels: $1 \mathrm{~F}+$ (sporadically positive TCs), $2 \mathrm{~F}+$ (dispersedly positive $\mathrm{TCs}$ ) and $3 \mathrm{~F}+$ (abundantly positive TCs); levels $1 \mathrm{~F}, 2 \mathrm{~F}$ and $3 \mathrm{~F}$.

Levels 2 and 3, as well as levels $2 \mathrm{~F}$ and $3 \mathrm{~F}$, were considered to denote high levels of nestin expression.

Statistical analyses. Kaplan-Meier estimates of survival functions were obtained using SAS 9.2 (SAS Institute Inc., Cary, NC, USA) statistical software. An event for overall survival 

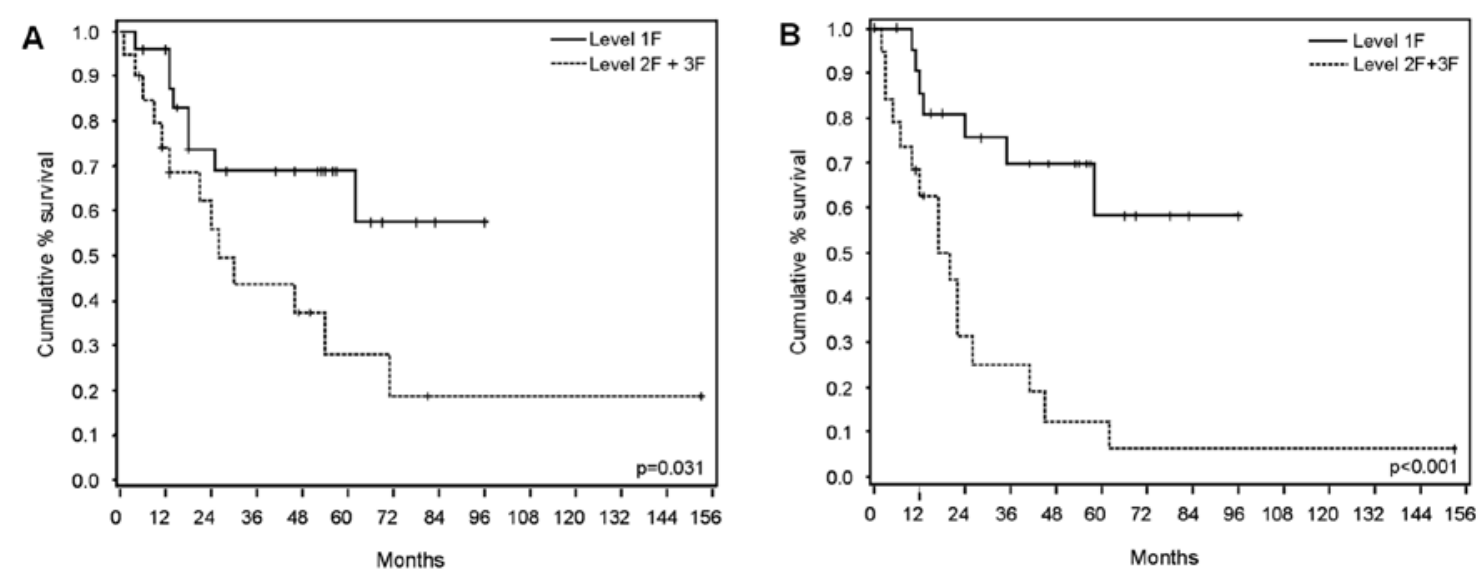

Figure 2. Kaplan-Meier curves of overall survival (OS) and event-free survival (EFS) stratified by the level of nestin expression examined by immunofluorescence. Patients with high levels of nestin expression $(2 \mathrm{~F}$ and $3 \mathrm{~F})$ had significantly inferior prognoses as compared to patients with low nestin expression $(1 \mathrm{~F})$, $\mathrm{P}$-value $(\mathrm{OS})=0.031(\mathrm{~A})$ and $\mathrm{P}$-value $(\mathrm{EFS})<0.001(\mathrm{~B})$.
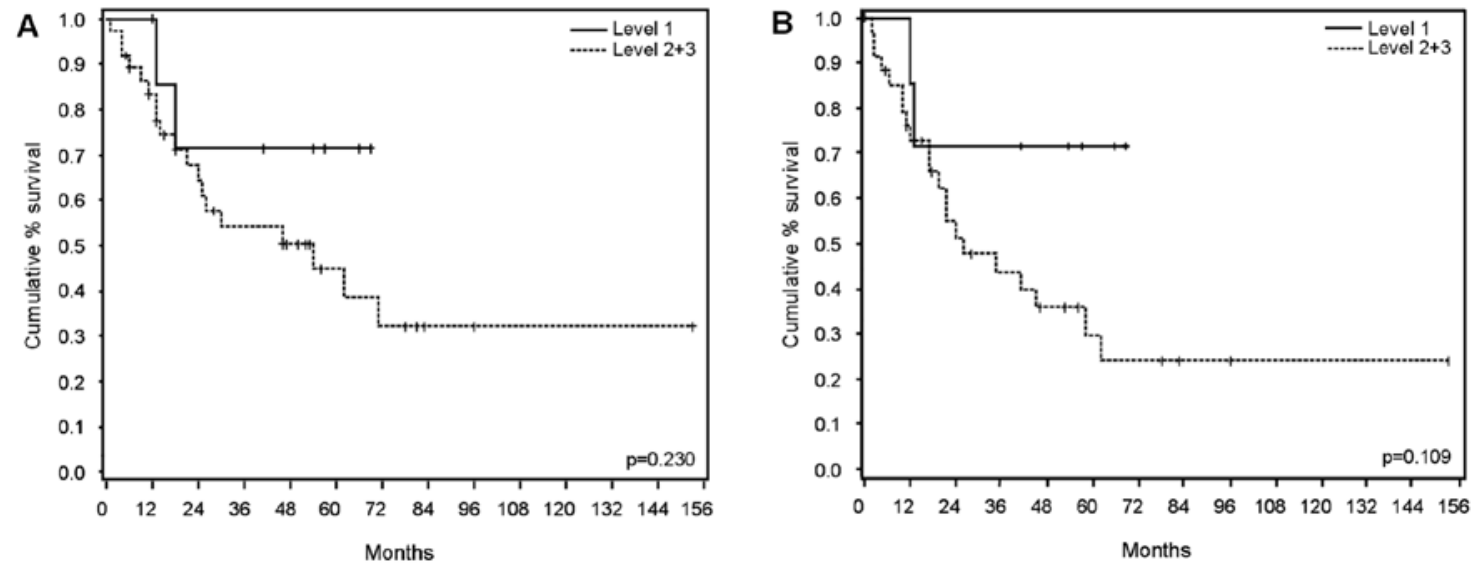

Figure 3. Kaplan-Meier OS and EFS curves stratified by the level of nestin expression as determined by immunohistochemistry. There were no significant differences between patients classified according to nestin expression (high nestin expressors vs. low nestin expressors). However, cases with high levels of nestin expression (levels 2 and 3) showed trends towards shorter survival. $\mathrm{p}(\mathrm{OS})=0.230$ (A) and $\mathrm{p}(\mathrm{EFS})=0.109$ (B).

(OS) was a death due to any cause. An event for event-free survival (EFS) was recurrence, progression, or death. The logrank test was used for comparisons between analyzed groups of patients with median survival times and 2-year survival rates indicated.

\section{Results}

Clinicopathological characteristics. Within the study group, four histological subtypes of high-grade osteosarcoma were identified. Osteoblastic osteosarcoma was the most frequent, with 28 cases $(62.2 \%)$. Chondroblastic, fibroblastic, and teleangiectatic subtypes were observed in 7 (15.6\%), 6 (13.3\%), and 4 cases (8.9\%), respectively. At diagnosis, no metastatic spreading was revealed in 37 patients $(82.2 \%)$. Regional lymph node involvement was present in 2 patients (4.4\%). Distant metastases to the lung and/or bone were found in 2 (4.4\%; M1a) and 6 patients (13.3\%; M1b), respectively. However, reliable information about nodal status or distant metastases was not available in 3 cases. One patient refused treatment, and another was only treated surgically because of advanced age (85-years old). Thus, neoadjuvant chemotherapy was administered to 43 patients (95.6\%). Gross total tumor removal was carried out in 36 cases $(80.0 \%)$, and marginal resection was performed in 2 cases (4.4\%). Thirty-eight patients received adjuvant chemotherapy (84.4\%).

Analysis of survival rates. The median follow-up period was 2.0 years for all 45 patients and 4.25 years for the 24 survivors. The median OS of all patients was 2.0 years. No statistically significant differences in survival rates between age groups (under 19 vs. over 19) were revealed ( $\mathrm{P}=0.088)$, even though younger patients displayed a longer median survival than did older patients. There was no significant difference between OS in males and females (median OS 27.0 months in males vs. 21.0 months in females; $\mathrm{P}=0.556$ ). On the contrary, the absence of detectable metastases at diagnosis was significantly associated with longer survival $(\mathrm{P}=0.023)$ as was gross total resection ( $\mathrm{P}<0.001)$, a lower Enneking stage (IIA; $\mathrm{P}=0.037$ ), and the achievement of complete remission $(\mathrm{P}<0.001)$. There was no statistically significant correlation between the histological subtype of osteosarcoma and $\mathrm{OS}(\mathrm{P}=0.869)$. The 2-year 
Table II. Prognostic value of nestin expression by KaplanMeier analysis.

\begin{tabular}{lccc}
\hline $\begin{array}{l}\text { Levels of nestin } \\
\text { expression }\end{array}$ & $\mathrm{N}(\%)$ & $\begin{array}{c}\text { P-value } \\
(\mathrm{OS})\end{array}$ & $\begin{array}{c}\text { P-value } \\
\text { (EFS) }\end{array}$ \\
\hline $\begin{array}{l}\text { IHC } \\
\text { Low }^{\mathrm{a}}\end{array}$ & $8(17.8)$ & $\mathrm{NS}$ & $\mathrm{NS}$ \\
High $^{\mathrm{b}}$ & $37(82.2)$ & & \\
IF & & & \\
Low $^{\mathrm{c}}$ & $25(55.6)$ & 0.031 & $<0.001$ \\
High $^{\mathrm{d}}$ & $20(44.5)$ & & \\
\hline
\end{tabular}

NS, not significant. ${ }^{a}<10 \%$ nestin-positive tumor cells, level $1+.{ }^{b}>10 \%$ nestin-positive tumor cells, levels $2+$ and $3+{ }^{c} \mathrm{Few}$ nestin-positive tumor cells, level $1 \mathrm{~F}+{ }^{\mathrm{d}}$ Dispersedly and abundantly nestin-positive tumor cells, levels $2 \mathrm{~F}+$ and $3 \mathrm{~F}+$.

survival rates for the patients with osteoblastic, fibroblastic, teleangiectatic, and chondroblastic variants were $69.5,66.7$, 66.7 and $35.7 \%$, respectively.

Analysis was also completed concerning EFS and the above-mentioned clinical variables with similar results to those obtained for OS. Univariate analysis did not show any significant differences in EFS based on age group, gender, or histological subtype of osteosarcoma. Additionally, M0 and NO status, complete tumor resection, a lower Enneking stage, and the achievement of complete remission were confirmed as favorable prognostic markers associated with longer EFS.

Analysis of nestin expression and its clinicopathological correlations. Nestin expression was identified using both immunohistochemistry and immunofluorescence in all examined osteosarcoma samples. However, the proportion of nestin-positive TCs ranged from cases with diffuse nestin positivity in a majority of TCs to cases with only sporadic nestin-positive cells. High levels of nestin expression detected by immunofluorescence (levels $2 \mathrm{~F}$ and $3 \mathrm{~F}$ ) were found in 37 patients $(82.2 \%)$ and were associated with a significantly inferior OS $(\mathrm{P}=0.031)$ and EFS probabilities $(\mathrm{P}<0.001)$ (Fig. 2). Using immunohistochemistry, trends toward shorter survival durations were revealed in cases with high levels of nestin expression (Fig. 3), but these differences did not reach statistical significance. The prognostic value of nestin expression is summarized in Table II.

\section{Discussion}

Prior to the introduction of multi-agent chemotherapy in the 1970s, amputation enabled a long-term survival rate of about $20 \%$ in patients with high-grade osteosarcoma $(45,46)$. However, the combination of aggressive polychemotherapy and surgery has improved the long-term survival rate to approximately $60 \%$. Despite intensive efforts, further advances in osteosarcoma patient prognoses have not been achieved in the last 30 years. In addition, there are no effective treatment protocols for primarily metastatic disease, recurrent or progressive cases, or refractory osteosarcomas unresponsive to conventional therapies. Therefore, it is necessary to determine entirely new therapeutic approaches.

This study follows our previous report, in which we described nestin expression in osteosarcoma for the first time (30). To date, nestin expression has been demonstrated in numerous types of malignancies (47). Furthermore, the evidence of nestin-positive tumor cells has been proven to correlate with dedifferentiation and advanced grade disease in some tumors (48-50). With regard to these findings, we sought to determine if high levels of nestin expression correlate with clinical outcome and, therefore, whether this expression could be a relevant prognostic marker for patients with high-grade osteosarcomas. According to our knowledge, the relationship between nestin expression in osteosarcoma tissue and clinical outcomes has not yet been studied. However, a number of studies investigating the prognostic value of nestin expression in various tumors have already been published. Several authors $(27,37,49,51)$ showed that nestin expression correlates with advanced-grade gliomas; additionally, some researchers also demonstrated a statistically significant correlation between nestin expression and poor prognosis in glioma patients $(27,37,51)$. Surprisingly, no prognostic implications of nestin expression were found in glioblastoma multiforme, i.e., in the most malignant form of astrocytoma $(52,53)$. In contrast, correlations between nestin expression and poorer clinical outcomes were documented in malignant melanoma (54), hepatocellular carcinoma (55), non-small cell lung carcinoma (56), gastric carcinoma (33) and prostate cancer (35).

In the present study, high levels of nestin expression detected by immunofluorescence in osteosarcoma samples were associated with significantly shorter OS and EFS. Using immunohistochemistry, no significant results were obtained regarding OS or EFS; the only propensities for longer OS and EFS were demonstrated in cases with low levels of nestin expression. To avoid misinterpretation of these results, especially non-specific those from immunostaining, positive (both external and internal) and negative controls were used in each sample analysis. Nevertheless, we are aware of the two main limitations of immunofluorescence labeling that may influence the specificity of this method. First, the immunofluorescence signal is enhanced by autofluorescence when formalin-fixed and paraffin-embedded materials are used. Thus, tissue cryosections are preferable when utilizing immunofluorescence staining. For this study, frozen tumor samples were not available in most cases. In addition, the quality of immunofluorescence imaging in cryosections of bone tissues is reduced. Second, immunofluorescence does not allow us to evaluate cytologic details and tissue architecture. Therefore, it was not always possible to reliably distinguish nestin-positive endothelial cells from nestin-positive tumor cells in osteosarcoma samples. For this reason, we cannot exclude some false-positive results of immunofluorescence labeling. These considerations could explain certain discrepancies between results obtained using immunohistochemistry and immunofluorescence. With regard to these explanations, immunohistochemistry seems to be a more sensitive and reproducible method for the evaluation of nestin expression. Considering the above information, we conclude that high levels of nestin expression do 
not seem to represent a powerful prognostic marker because there were no statistically significant differences between nestin expression as detected by immunohistochemistry and clinical outcomes.

As has been reported by many authors $(12,57,58)$, we also found that seemingly having a localized disease at diagnosis, complete tumor resection, a lower Enneking stage, and the achievement of complete remission are favorable markers associated with longer OS. The relationship between the histological subtype of high-grade osteosarcomas and clinical outcomes is discussed in only a few studies (59-61). In the studies of Picci et al (59) and Bacci et al (61), the authors evaluated histological subtypes of 227 and 1058 patients with high-grade central osteosarcomas, respectively. Both studies reported the same conclusion that fibroblastic and teleangiectatic variants showed higher proportions of good responders, whereas a lower proportion of good responders was found in the osteoblastic subtype. Furthermore, the chondroblastic osteosarcoma subtype had the smallest percentage of good responders to neoadjuvant chemotherapy. Similarly, fibroblastic and teleangiectatic osteosarcomas had significantly better prognoses than did the osteoblastic and chondroblastic histotypes. In our study consisting of 45 patients, no statistically significant differences in survival rates among the histological subtypes were found; however, patients of the chondroblastic variant displayed shorter survival periods.

In conclusion, a variable frequency of nestin-positive tumor cells was demonstrated in all examined samples of high-grade osteosarcomas. We found statistically significant correlations between high levels of nestin expression detected by immunofluorescence and shorter survival rates. However, only statistically insignificant trends for shorter survival in patients with high levels of nestin expression were revealed using the generally more sensitive immunohistochemistry. Taking together, these findings indicate that high levels of nestin expression do not represent a strong prognostic factor for patients with high-grade osteosarcomas. With regard to the fact that nestin has been described as a cancer stem cell marker in solid tumors of various origin, the co-expression of nestin with other potential cancer stem cell markers in osteosarcomas should be analyzed in future research. The detection of a true cancer stem cell phenotype in osteosarcomas will help in giving more precise prognoses to osteosarcoma patients.

\section{Acknowledgements}

The authors are grateful to all patients who contributed to this study. We would like to thank Mrs. Marcela Vesela, Mrs. Katerina Doruskova, Mrs. Lucie Jerabkova and Mr. Tomas Pakosta for their skillful technical assistance. We are grateful to Professor Boris Habanec for providing tumor samples from the files of the Department of Pathology, University Hospital Brno. This study was supported by grant VZ MSM0021622415.

\section{References}

1. Mirabello L, Troisi RJ and Savage SA: Osteosarcoma incidence and survival rates from 1973 to 2004: data from the Surveillance, Epidemiology, and Results Program. Cancer 115: 1531-1543, 2009.
2. Feugeas O, Guriec N, Babin-Boilletot A, et al: Loss of heterozygosity of the RB gene is a poor prognostic factor in patients with osteosarcoma. J Clin Oncol 14: 467-472, 1996.

3. Benassi MS, Molendini L, Gamberi G, et al: Alteration of $\mathrm{pRb} /$ p16/cdk4 regulation in human osteosarcoma. Int J Cancer 84: 489-493, 1999.

4. Park YB, Kim HS, Oh JH and Lee SH: The co-expression of p53 protein and P-glycoprotein is correlated to a poor prognosis in osteosarcoma. Int Orthop 24: 307-310, 2001.

5. Smida J, Baumhoer D, Rosemann M, et al: Genomic alterations and allelic imbalances are strong prognostic predictors in osteosarcoma. Clin Cancer Res 16: 4256-4267, 2010.

6. Huvos AG: Osteogenic sarcoma of bones and soft tissues in older person. A clinicopathologic analysis of 117 patients older than 60 years. Cancer 57: 1442-1449, 1986.

7. Hamre MR, Severson RK, Chuba P, Lucas DR, Thomas RL and Mott MP: Osteosarcoma as a second malignant neoplasm. Radiother Oncol 65: 153-157, 2002.

8. Kager L, Zoubek A, Pötschger U, et al: Primary metastatic osteosarcoma: presentation and outcome of patients treated on neoadjuvant Cooperative Osteosarcoma Study Group protocols. J Clin Oncol 21: 2011-2018, 2003.

9. Eilber FC, Rosen G, Eckardt J, et al: Treatment-induced pathologic necrosis: a predictor of local recurrence and survival in patients receiving neoadjuvant therapy for high-grade extremity soft tissue sarcomas. J Clin Oncol 19: 3203-3209, 2001.

10. Machak GN, Tkachev SI, Solovyev YN, et al: Neoadjuvant chemotherapy and local radiotherapy for high-grade osteosarcoma of the extremities. Mayo Clin Proc 78: 147-155, 2003.

11. Mohseny AB, Szuhai K, Romeo S, et al: Osteosarcoma originates from mesenchymal stem cells in consequence of aneuploidization and genomic loss of Cdkn2. J Pathol 219: 294-305, 2009.

12. Bielack SS, Kempf-Bielack B, Delling G, et al: Prognostic factors in high-grade osteosarcoma of the extremities or trunk: an analysis of 1,702 patients treated on neoadjuvant cooperative osteosarcoma study group protocols. J Clin Oncol 20: 776-790, 2002.

13. Picci P, Mercuri M, Ferrari S, et al: Survival in high-grade osteosarcoma: improvement over 21 years at a single institution. Ann Oncol 21: 1366-1373, 2010.

14. Goorin AM, Harris MB, Bernstein M, et al: Phase II/III trial of etoposide and high-dose ifosfamide in newly diagnosed metastatic osteosarcoma: a pediatric oncology group trial. J Clin Oncol 20: 426-433, 2002.

15. Ek ET, Ojaimi J, Kitagawa Y and Choong PF: Does the degree of intratumoural microvessel density and VEGF expression have prognostic significance in osteosarcoma? Oncol Rep 16: 17-23, 2006.

16. Duggal $\mathrm{N}$ and Hammond RR: Nestin expression in ganglioglioma. Exp Neurol 174: 89-95, 2002.

17. Lendahl U, Zimmerman LB and McKay RD: CNS stem cells express a new class of intermediate filament protein. Cell 60: 585-595, 1990

18. Holland EC: A mouse model for glioma: biology, pathology, and therapeutic opportunities. Toxicol Pathol 28: 171-177, 2000.

19. Sahlgren CM, Mikhailov A, Hellman J, Chou YH, Lendahl U, Goldman RD and Eriksson JE: Mitotic reorganization of the intermediate filament protein nestin involves phosphorylation by cdc2 kinase. J Biol Chem 276: 16456-16463, 2001.

20. Sahlgren CM, Pallari HM, He T, Chou YH, Goldman RD and Eriksson JE: A nestin scaffold links Cdk5/p35 signaling to oxidant-induced cell death. EMBO J 25: 4808-4819, 2006.

21. Chou YH, Khuon S, Herrmann H and Goldman RD: Nestin promotes the phosphorylation-dependent disassembly of vimentin intermediate filaments during mitosis. Mol Biol Cell 14: 1468-1478, 2003

22. Lin RC, Matesic DF, Marvin M, McKay RD and Brüstle O: $\mathrm{Re}$-expression of the intermediate filament nestin in reactive astrocytes. Neurobiol Dis 2: 79-85, 1995.

23. Niki T, Pekny M, Hellemans K, et al: Class VI intermediate filament protein nestin is induced during activation of rat hepatic stellate cells. Hepatology 29: 520-527, 1999.

24. Aärimaa V, Kääriäinen M, Vaittinen S, Tanner J, Järvinen T, Best T and Kalimo H: Restoration of myofiber continuity after transection injury in the rat soleus. Neuromuscul Disord 14: 421-428, 2004.

25. El-Helou V, Dupuis J, Proulx C, et al: Resident nestin ${ }^{+}$neurallike cells and fibers are detected in normal and damaged rat myocardium. Hypertension 46: 1219-1225, 2005. 
26. Tsujimura T, Makiishi-Shimobayashi C, Lundkvist J, et al: Expression of the intermediate filament nestin in gastrointestinal stromal tumors and interstitial cells of Cajal. Am J Pathol 158: 817-823, 2001.

27. Strojnik T, Røsland GV, Sakariassen PO, Kavalar R and Lah T: Neural stem cell markers, nestin and musashi proteins, in the progression of human glioma: correlation of nestin with prognosis of patient survival. Surg Neurol 68: 133-143, 2007.

28. Kleeberger W, Bova GS, Nielsen ME, Herawi M, Chuang AY, Epstein JI and Berman DM: Roles for the stem cell associated intermediate filament Nestin in prostate cancer migration and metastasis. Cancer Res 67: 9199-9206, 2007.

29. Brychtova S, Fiuraskova M, Hlobilková A, Brychta T and Hirnak J: Nestin expression in cutaneous melanomas and melanocytic nevi. J Cutan Pathol 34: 370-375, 2007.

30. Veselska R, Hermanova M, Loja T, et al: Nestin expression in osteosarcomas and derivation of nestin/CD133 positive osteosarcoma cell lines. BMC Cancer 8: 300, 2008.

31. Sellheyer K, Nelson P and Krahl D: Dermatofibrosarcoma protuberans: a tumour of nestin-positive cutaneous mesenchymal stem cells? Br J Dermatol 161: 1317-1322, 2009.

32. Yamada H, Takano T, Ito Y, Matsuzuka F, Miya A, et al: Expression of nestin mRNA is a differentiation marker in thyroid tumors. Cancer Lett 280: 61-64, 2009.

33. Kim HS, Kang HS, Messam CA, Min KW and Park CS Comparative evaluation of angiogenesis in gastric adenocarcinoma by nestin and CD34. Appl Immunohistochem Mol Morphol 10: 121-127, 2002

34. Teranishi N, Naito Z, Ishiwata T, et al: Identification of neovasculature using nestin in colorectal cancer. Int J Oncol 30: 593-603, 2007.

35. Gravdal K, Halvorsen OJ, Haukaas SA and Akslen LA: Proliferation of immature tumor vessels is a novel marker of clinical progression in prostate cancer. Cancer Res 69: 4708-4715, 2009.

36. Maslov AY, Barone TA, Plunkett RJ and Pruitt SC: Neural stem cell detection, characterization, and age-related changes in the subventricular zone of mice. J Neurosci 24: 1726-1733, 2004.

37. Zhang M, Song T, Yang L, Chen R, Wu L, Yang Z and Fang J: Nestin and CD133: valuable stem cell-specific markers for determining clinical outcome of glioma patients. J Exp Clin Cancer Res 27: 85, 2008.

38. Deleyrolle LP, Harding A, Cato K, et al: Evidence for labelretaining tumour-initiating cells in human glioblastoma. Brain 134: 1331-1343, 2011.

39. Gu G, Yuan J, Wills M and Kasper S: Prostate cancer cells with stem cell characteristics reconstitute the original human tumor in vivo. Cancer Res 67: 4807-4815, 2007.

40. Guzmán-Ramírez N, Völler M, Wetterwald A, et al: In vitro propagation and characterization of neoplastic stem/progenitorlike cells from human prostate cancer tissue. Prostate 69: 1683-1693, 2009.

41. Jimeno A, Feldmann G, Suárez-Gauthier A, et al: A direct pancreatic cancer xenograft model as a platform for cancer stem cell therapeutic development. Mol Cancer Ther 8: 310-314, 2009.

42. Bentivegna A, Conconi D, Panzeri E, et al: Biological heterogeneity of putative bladder cancer stem-like cell populations from human bladder transitional cell carcinoma samples. Cancer Sci 101: 416-424, 2010.

43. Okuno K, Ohta S, Kato H, Taga T, Sugita K and Takeuchi Y Expression of neural stem cell markers in malignant rhabdoid tumor cell lines. Oncol Rep 23: 485-492, 2010.

44. Sana J, Zambo I, Skoda J, et al: CD133 expression and identification of CD133/nestin positive cells in rhabdomyosarcomas and rhabdomyosarcoma cell lines. Anal Cell Pathol (Amst) 34: 303-318, 2011 .
45. Marcove RC, Mike V, Hajek JV, Levin AG and Hutter RV: Osteogenic sarcoma under the age of twenty-one. A review of one hundred and forty-five operative cases. J Bone Joint Surg Am 52: 411-423, 1970.

46. Bacci G, Picci P, Ferrari S, et al: Neoadjuvant chemotherapy for non-metastatic osteosarcoma of the extremities: the recent experience at the Rizzoli Institute. Cancer Treat Res 62: 299-308, 1993.

47. Krupkova O Jr, Loja T, Zambo I and Veselska R: Nestin expression in human tumors and tumor cell lines. Neoplasma 57 291-298, 2010.

48. Dahlstrand J, Collins VP and Lendahl U: Expression of the class VI intermediate filament nestin in human central nervous system tumors. Cancer Res 52: 5334-5341, 1992.

49. Maderna E, Salmaggi A, Calatozzolo C, Limido L and Pollo B: Nestin, PDGFRbeta, CXCL12 and VEGF in glioma patients: different profiles of (pro-angiogenic) molecule expression are related with tumor grade and may provide prognostic information. Cancer Biol Ther 6: 1018-1024, 2007.

50. $\mathrm{Li} \mathrm{H}$, Cherukuri $\mathrm{P}, \mathrm{Li} \mathrm{N}$, et al: Nestin is expressed in the basal/ myoepithelial layer of the mammary gland and is a selective marker of basal epithelial breast tumors. Cancer Res 67: 501-510, 2007.

51. Wan F, Herold-Mende C, Campos B, et al: Association of stem cell-related markers and survival in astrocytic gliomas. Biomarkers 16: 136-143, 2011.

52. Chinnaiyan P, Wang M, Rojiani AM, et al: The prognostic value of nestin expression in newly diagnosed glioblastoma: report from the Radiation Therapy Oncology Group. Radiat Oncol 3: 32,2002 .

53. Kim KJ, Lee KH, Kim HS, Moon KS, Jung TY, Jung S and Lee MC: The presence of stem cell marker-expressing cells is not prognostically significant in glioblastomas. Neuropathology 31: 494-502, 2011.

54. Piras F, Perra MT, Murtas D, et al: The stem cell marker nestin predicts poor prognosis in human melanoma. Oncol Rep 23: $17-24,2010$

55. Yang XR, Xu Y, Yu B, et al: High expression levels of putative hepatic stem/progenitor cell biomarkers related to tumour angiogenesis and poor prognosis of hepatocellular carcinoma. Gut 59: 953-962, 2010.

56. Ryuge S, Sato Y, Wang GQ, et al: Prognostic significance of nestin expression in resected non-small cell lung cancer. Chest 139: 862-869, 2011.

57. Hudson M, Jaffe MR, Jaffe N, et al: Pediatric osteosarcoma: therapeutic strategies, results, and prognostic factors derived from a 10-year experience. J Clin Oncol 8: 1988-1997, 1990.

58. Provisor AJ, Ettinger LJ, Nachman JB, et al: Treatment of nonmetastatic osteosarcoma of the extremity with preoperative and postoperative chemotherapy: a report from the Children's Cancer Group. J Clin Oncol 15: 76-84, 1997.

59. Picci P, Bacci G, Campanacci M, et al: Histologic evaluation of necrosis in osteosarcoma induced by chemotherapy. Regional mapping of viable and nonviable tumor. Cancer 56: 1515-1521, 1985.

60. Hauben EI, Weeden S, Pringle J, Van Marck EA and Hogendoorn PC: Does the histological subtype of high-grade central osteosarcoma influence the response to treatment with chemotherapy and does it affect overall survival? A study on 570 patients of two consecutive trials of the European Osteosarcoma Intergroup. Eur J Cancer 38: 1218-1225, 2002.

61. Bacci G, Bertoni F, Longhi A, et al: Neoadjuvant chemotherapy for high-grade central osteosarcoma of the extremity. Histologic response to preoperative chemotherapy correlates with histologic subtype of the tumor. Cancer 97: 3068-3075, 2003. 